\title{
Risk of colorectal adenomas in patients with a family history of colorectal cancer: some implications for screening programmes
}

\author{
J F Aitken, C J Bain, $M$ Ward, V Siskind, R MacLennan
}

\begin{abstract}
Background and aims-Most colorectal cancers (CRC) arise in colorectal adenomas. A case-control study was conducted to see whether a family history of CRC is associated with a higher prevalence of colorectal adenomas.

Subjects-Subjects were drawn from all patients who underwent colonoscopy at the Royal Brisbane Hospital between 1980-1982 and 1985, and included 141 cases with colorectal adenomas diagnosed at colonoscopy and 882 controls who were free of polyps at colonoscopy.

Methods-The prevalence of family history of CRC was compared between patients with adenomas and negative colonoscopy controls.

Results-Overall, patients with one first degree relative with CRC were at no greater risk for adenomas at colonoscopy than patients with no family history (odds ratio $(O R)=0.8,95 \%$ confidence intervals $(C I)=0.4,1.5)$. Patients with two or more affected first degree relatives had a more than doubled risk for adenomas $(O R=2 \cdot 3$, $95 \% \mathrm{CI}=0 \cdot 5,8 \cdot 2)$, and were also more likely to carry moderately or severely dysplastic adenomas $(\mathrm{OR}=14 \cdot 1,95 \%$ $\mathrm{CI}=2 \cdot 0,62 \cdot 9$ ).

Conclusions-These findings are consistent with the hypothesis that some families, in addition to those with familial adenomatous polyposis, have an increased susceptibility to develop colorectal adenomas, and that adenomas in such families may have a greater tendency to undergo malignant transformation.

(Gut 1996; 39: 105-108)
\end{abstract}

Keywords: colorectal cancer, family history, adenomas, screening.

History of colorectal cancer (CRC) in a first degree relative increases the risk of this disease by twofold to threefold. ${ }^{1}$ As most CRCs arise in pre-existing adenomas, ${ }^{2}$ one would expect either that the prevalence of adenomas would be higher among subjects with a positive family history, or that a larger proportion of their adenomas would undergo malignant transformation.

The extent to which genetic susceptibility plays a part in the $90 \%$ or so of new cases of CRC not associated with familial adenomatous polyposis (FAP) or hereditary non-polyposis colorectal cancer (HNPCC) ${ }^{3}$ is unknown. If inherited genetic factors are present, it is possible that they may affect varying stages of the adenoma-carcinoma sequence. Thus, in some families, while the prevalence of colorectal adenomas may not be increased, adenomas may progress to CRC more frequently than usual (similar to the situation in HNPCC $^{4}$ ). We sought to discover if a family history of CRC not due to FAP or HNPCC is associated with an increased prevalence of adenomas in general, or with an increased proportion of the large, dysplastic adenomas most likely to undergo malignant change. ${ }^{5}$

\section{Methods}

Study subjects

Cases and controls were identified on the basis of findings at colonoscopy, and were drawn retrospectively from all patients who underwent colonoscopy at the Royal Brisbane Hospital during 1980-1982 and 1985, were alive and aged below 75 years at time of study, and had a known current address. (Colonoscopy patients in 1983-1984 were excluded as they were involved in another project.) History of gastrointestinal disease and cancer, indications for colonoscopy, and colonoscopy findings were recorded from hospital charts, physicians' records, and colonoscopy reports, and patients younger than 20 years at colonoscopy, or with a history of colorectal resection, CRC, FAP, or inflammatory bowel disease were excluded. To avoid possible selection bias, 27 patients (six with polyps) whose sole indication for colonoscopy was a positive family history of CRC were also excluded.

For remaining patients, copies of histopathology reports were sought for all polyps removed at colonoscopy. Cases were defined as patients with histologically confirmed adenomatous polyps diagnosed at the study colonoscopy, and a few eligible patients who had had adenomatous polyps removed within two years prior to the study period and who returned for a follow up colonoscopy during the study years. Controls were defined as patients with no polyps at study colonoscopy, nor with any history of colorectal polyps.

\section{Data collection}

A questionnaire mailed to the cases and controls asked about their history of bowel conditions and symptoms, reasons for initial

\author{
Brisbane Hospital, \\ Accepted for publication \\ 30 January 1996 \\ Correspondence to: \\ Dr J F Aitken, Queensland \\ Institute of Medical

Department of Social
and Preventive
Medicine, University
of Queensland,
Brisbane
J F Aitken
C J Bain
V Siskind
Queensland Institute
of Medical Research,
Brisbane
J F Aitken
R MacLennan
Department of
Gastroenterology,
Royal Brisbane
Hospital, Brisbane
M Ward
Correspondence to:
Dr J F Aitken, Queensland
Institute of Medical
Research, Post Office Royal
Brisbane Hospital,
Queensland, Australia 4029
Accepted for publication
30 January 1996


presentation to their doctor prior to colonoscopy, and family medical history. The family history questions asked for names of all first degree relatives (parents, siblings, and children), their current ages or ages at death, whether any of these, or other, relatives had had cancer or polyps of the bowel, bowel obstruction, other bowel diseases or cancer at other sites, and if so, the ages when these conditions occurred.

\section{Histological classification of polyps}

All histological examinations during the study years were performed at the Royal Brisbane Hospital or in one of two large private laboratories using standard procedures. Polyps were classified as hyperplastic; or tubular, tubulovillous, or villous adenomas, and given a histological grade of mild, moderate, or severe dysplasia, using standard criteria. ${ }^{6}$

\section{Confirmation of reported family history of colorectal cancer}

Medical confirmation of the diagnosis of CRC was sought for all first degree relatives reported by cases and controls to have had CRC, and for a sample of first degree relatives for whom it was not reported. ${ }^{7}$ We estimate that $90 \%$ of all families with a true positive history were correctly reported, as were $97 \%$ of families with no such history. Cases were slightly more accurate than controls in reporting their relatives' CRC histories. As odds ratios changed little when corrected for this small amount of misclassification, ${ }^{7}$ the present analysis is based on patients' original reports of their relatives' CRC histories.

\section{Data analysis}

Odds ratios (OR), calculated using multiple logistic regression analysis, were used to measure the association between presence of adenomas at colonoscopy and a positive family history in one or more first degree relatives. Ninety five per cent confidence intervals (CI) for the $O R$ were computed by standard methods. ${ }^{8}$ ORs were adjusted for known or suspected risk factors for colorectal adenomas or carcinoma (age, sex, socioeconomic indicators

TABLE I Histological types and features of polyps found at colonoscopy in 141 cases, Brisbane, Australia, 1980-1982, and 1985

\begin{tabular}{|c|c|c|c|c|c|c|}
\hline \multirow[b]{2}{*}{$\begin{array}{l}\text { Features } \\
\text { of polyps }\end{array}$} & \multirow[b]{2}{*}{$\begin{array}{l}\text { Total } \\
\text { polyps }\end{array}$} & \multicolumn{3}{|l|}{ Adenomas } & \multirow[b]{2}{*}{$\begin{array}{l}\text { Hyperplastic } \\
\text { polyps }\end{array}$} & \multirow[b]{2}{*}{$\begin{array}{l}\text { Unspecified } \\
\text { type }\end{array}$} \\
\hline & & $\begin{array}{l}\text { Total } \\
\text { adenomas }\end{array}$ & $\begin{array}{l}\text { Histologically } \\
\text { confirmed } \\
\text { adenomas }\end{array}$ & $\begin{array}{l}\text { Not confirmed } \\
\text { (reported by } \\
\text { colonoscopist) }\end{array}$ & & \\
\hline Total & 371 & 222 & 163 & 59 & 10 & 139 \\
\hline $\begin{array}{c}\text { Diameter (mm) } \\
1-5 \\
6-10 \\
11-15 \\
>15 \\
\text { Unknown }\end{array}$ & $\begin{array}{l}110(39 \cdot 3)^{\star} \\
80(28 \cdot 6) \\
48(17 \cdot 1) \\
42(15 \cdot 0) \\
91\end{array}$ & $\begin{array}{l}38(19 \cdot 7) \\
66(34 \cdot 2) \\
47(24 \cdot 4) \\
42(21 \cdot 8) \\
29\end{array}$ & $\begin{array}{c}28(17 \cdot 4) \\
46(28 \cdot 6) \\
45(28 \cdot 0) \\
42(26 \cdot 1) \\
2\end{array}$ & $\begin{array}{l}10(31 \cdot 3) \\
20(62 \cdot 5) \\
2(6 \cdot 3) \\
0 \\
27\end{array}$ & $\begin{array}{l}8(80 \cdot 0) \\
2(20 \cdot 0)\end{array}$ & $\begin{array}{l}64(83 \cdot 1) \\
12(15 \cdot 6) \\
1(1 \cdot 3) \\
0 \\
62\end{array}$ \\
\hline $\begin{array}{l}\text { Location } \\
\text { Distal† } \\
\text { Proximal } \\
\text { Unknown }\end{array}$ & $\begin{array}{l}275(79 \cdot 5) \\
71(20 \cdot 5) \\
25\end{array}$ & $\begin{array}{r}198(89 \cdot 2) \\
24(10 \cdot 8)\end{array}$ & $\begin{array}{c}150(92 \cdot 0) \\
13(8 \cdot 0)\end{array}$ & $\begin{array}{l}48(81 \cdot 4) \\
11(18 \cdot 6)\end{array}$ & $\begin{array}{l}8(80 \cdot 0) \\
2(20 \cdot 0)\end{array}$ & $\begin{array}{l}69(60 \cdot 5) \\
45(39 \cdot 5) \\
25\end{array}$ \\
\hline
\end{tabular}

*Numbers in brackets are percentages of column totals, excluding unknown. †Rectum, sigmoid, and descending colon. (health insurance status, education), physical activity, smoking history, history of rectal bleeding, and presentation or referral because of family history of CRC) by including these in the regression models.

\section{Results}

Approximately 3600 colonoscopies were performed at the Royal Brisbane Hospital during the study years. Of these, 1449 were eligible, and 374 of them had one or more polyps diagnosed during the study period $(84 \%)$ or within the previous two years $(16 \%)$. We obtained histopathology reports for $189(51 \%)$ of these patients. Thirty one with hyperplastic polyps only were excluded, leaving 158 patients with at least one confirmed adenoma. Controls were the 1075 eligible patients without polyps. Almost three quarters of these had no colorectal pathology at colonoscopy. Diagnoses among the rest included diverticula, melanosis coli, and colitis. A total of 141 cases $(89 \cdot 2 \%)$ and 882 controls $(82.0 \%)$ returned the mailed questionnaire, and are the subjects of the analysis.

More cases than controls were male $(50.4 \%$ versus $35.8 \%$ ) and were aged 40 years or older $(92 \cdot 9 \%$ versus $77 \cdot 8 \%)$. Most patients presented because of bowel symptoms, most commonly rectal bleeding, abdominal pain, or change in bowel habit, with rectal bleeding being more prevalent among cases $(61 \cdot 2 \%$ versus $36 \cdot 8 \%$ ). For a few patients $(5 \cdot 4 \%)$, a positive family history was given among other reasons for presentation. No families satisfied the Amsterdam criteria for HNPCC. ${ }^{9}$

\section{Pathology findings}

The 141 cases carried a total of 371 polyps, including 163 histologically confirmed adenomas (Table I). These included 56 tubular, 76 tubulovillous, and seven villous adenomas. Morphology was unspecified for 24. Some 123 cases $(87 \cdot 2 \%)$ had a single confirmed adenoma, and the remaining 18 cases between two and four each.

Polyp diameter was obtained from colonoscopy or histopathology reports for 280 polyps. The histological measurement was used when both were available. There were similar proportions of adenomas (confirmed and unconfirmed combined) under (53.9\%) and over 10 $\mathrm{mm}$ in diameter $(46 \cdot 1 \%)$ (Table I). Most adenomas $(89.2 \%)$ were located in the distal large bowel (rectum, sigmoid, and descending colon). Six adenomas were reported as moderately dysplastic and 11 severely dysplastic. (By definition, all adenomas are dysplastic. During the study years, mild dysplasia was usually not mentioned in the pathology report.)

\section{Family history of colorectal cancer and risk of} colorectal adenomas

Family sizes and relatives' age distributions were almost identical for cases and controls, and so were ignored in subsequent analyses. A smaller proportion of cases ( 11 of $141,7 \cdot 8 \%$ ) than controls ( 85 of $882,9.6 \%$ ) reported 
TABLE II Family history of colorectal cancer among first degree relatives of 141 cases with histologically confirmed colorectal adenomas, and 882 controls without polyps who underwent colonoscopy in Brisbane, Australia, 1980-1982, and 1985

\begin{tabular}{|c|c|c|c|c|c|c|}
\hline \multirow[b]{2}{*}{$\begin{array}{l}\text { Number of } \\
\text { first degree } \\
\text { relatives with } \\
\text { colorectal cancer }\end{array}$} & \multirow[b]{2}{*}{$\begin{array}{l}\text { Controls } \\
(n=882)\end{array}$} & \multirow[b]{2}{*}{$\begin{array}{l}\text { All } \\
\text { cases } \\
(n=141)\end{array}$} & \multicolumn{4}{|l|}{ Cases } \\
\hline & & & $\begin{array}{l}\text { Cases with } \\
\text { adenomas } \\
>10 \text { mm } \\
\text { in diameter } \\
(n=82)\end{array}$ & $\begin{array}{l}\text { Cases with } \\
\text { tubulovillous } \\
\text { or villous } \\
\text { adenomas } \\
(n=71)\end{array}$ & $\begin{array}{l}\text { Cases with } \\
\text { moderately } \\
\text { or severely } \\
\text { dysplastic } \\
\text { adenomas } \\
(n=17)\end{array}$ & $\begin{array}{l}\text { Cases with } \\
\text { adenomas } \\
>10 \mathrm{~mm} \text {, } \\
\text { any dysplasia, } \\
\text { and villous } \\
(n=18)\end{array}$ \\
\hline $\begin{array}{l}\text { Any relatives } \\
1 \text { Relative only } \\
\geqslant 2 \text { Relatives }\end{array}$ & $\begin{array}{l}93(10.5)^{\star} \\
85(9 \cdot 6) \\
8(0.9)\end{array}$ & $\begin{array}{r}14(9 \cdot 9) \\
11(7 \cdot 8) \\
3(2 \cdot 1)\end{array}$ & $\begin{array}{l}8(9 \cdot 8) \\
6(7 \cdot 3) \\
2(2 \cdot 4)\end{array}$ & $\begin{array}{l}7(9.9) \\
6(8.5) \\
1(1.4)\end{array}$ & $\begin{array}{l}3(17 \cdot 6) \\
1(5 \cdot 9) \\
2(11 \cdot 8)\end{array}$ & $\begin{array}{l}3(16 \cdot 7) \\
1(5 \cdot 6) \\
2(11 \cdot 1)\end{array}$ \\
\hline
\end{tabular}

${ }^{\star}$ Numbers in brackets are percentages of column totals.

having a single first degree relative with CRC $(\mathrm{OR}=0.8,95 \% \mathrm{CI}=0.4,1.5) \quad$ (Table II). However, the proportion with two or more positive relatives was twice as great among cases (three of $141,2 \cdot 1 \%$ ) as controls (eight of $882,0 \cdot 9 \%)(\mathrm{OR}=2 \cdot 3, .95 \% \mathrm{CI}=0 \cdot 5,8 \cdot 2)$. As cases here were few, the $\mathrm{CI}$ is wide, and the play of chance cannot be excluded. The results changed little after adjustment for potential confounding by age, sex, health insurance status, education, physical activity, smoking history, history of rectal bleeding, and presentation or referral because of family history in addition to bowel symptoms.

To examine the relation between family history and malignant potential of adenomas, we compared the prevalence of positive family history among cases with large, dysplastic, or villous adenomas with that among controls (Table II). When each criterion was examined separately, the presence of a positive family history was most strongly linked to moderate or severe dysplasia (positive family history in any first degree relatives was present in three of $17(17.6 \%)$ such cases compared with 93 of $882(10.5 \%)$ controls (OR $=1 \cdot 8,95 \%$ CI 0.4 , 5.7)). A similar pattern was seen for the small group of cases whose adenomas showed all three indicators of malignant potential $(\mathrm{OR}=1 \cdot 7,95 \% \mathrm{CI}=0 \cdot 4,5 \cdot 3)$. In the presence of two or more positive relatives, these ORs were $14 \cdot 1(95 \% \mathrm{CI}=2 \cdot 0,62 \cdot 9)$ and $13 \cdot 2(95 \%$ $\mathrm{CI}=1 \cdot 9,58 \cdot 2)$, respectively. Although it seems all the effect may lie with the strong family history, cases are too few to truly distinguish real differences. Neither size nor villous pattern modified the general family history association.

\section{Discussion}

The hypothesis that a history of CRC in any first degree relatives confers an increased risk of adenomas in general was not supported by these data. This parallels another Australian study, ${ }^{10}$ but is at odds with other case-control studies, ${ }^{11-13}$ which have found twofold to fivefold increased risks for adenomas associated with any positive family history of CRC. Two of them ${ }^{12} 13$ almost certainly overestimated the relation, as colonoscopy patients were compared with asymptomatic (nongastrointestinal) patients. Such a contrast is likely to be biased as family history itself is a reason for referral for colonoscopy. In the other two studies, self reported family history was not verified, little was said about reasons for referral, it is not clear that HNPCC families were excluded, and patients with different strengths of family history were combined in the analyses. Thus the true overall relation remains unclear.

In the one controlled, prospective colonoscopy study of which we are aware, the prevalence of adenomas among patients with a family history was $14 \%$, and in the rest $8 \%$, a difference statistically non-significant. ${ }^{14}$ Among patients with two positive first degree relatives, adenomas were almost twice as prevalent $(24 \%)$ as among those with only one $(13 \%)$. Consistent with this, and with reports of colonoscopy screening of patients with a positive family history, ${ }^{15} 16$ our results also suggest that patients with two or more first degree relatives with CRC may be at increased risk for colorectal adenomas, and possibly at greatly increased risk for adenomas with moderate to severe dysplasia. This supports the notion that some families, in addition to those with FAP, have an inherited susceptibility to develop colorectal adenomas, ${ }^{17}$ and that such adenomas may have a heightened potential to progress to carcinoma. ${ }^{5}$

All patients in this study, both cases and controls, sought medical attention and were referred for colonoscopy because of bowel symptoms. Although it is clear that family history itself plays some part in a patient's decision to present to their doctor when they develop bowel symptoms, this should apply equally to cases and controls, and is therefore unlikely to cause a bias in this study. In fact, negative colonoscopy controls, as used here, are in theory an ideal comparison group for the cases. In support of this, a similar proportion of cases and controls stated that a concern about family history was one of the reasons for their presentation to their doctor, and, further, results were unchanged after adjusting in the analysis for whether or not family history (in addition to bowel symptoms) was one of the reasons for the patient's presentation or referral.

The lifetime risk for CRC in Australia, as in Britain, is approximately 1 in 25 . If family history increases risk by a factor of 2 or 3, this translates to a lifetime risk for first degree relatives of CRC patients of approximately 1 in 10 , on average. Using life table methods and Lovett's original pedigrees, ${ }^{18}$ Houlston et al have calculated that this increased risk is not consistent across all families of CRC patients, but increases with the strength of family history. ${ }^{19}$ Our results support this, and suggest that colonoscopy screening among people with one first degree relative with CRC would yield no more adenomas than would be found in others of the same age and sex. Our findings do imply that people with two or more first degree relatives with CRC may be at greater risk for colorectal adenomas, and therefore might gain most from colonoscopy screening, particularly if they also have a relative excess of more dysplastic lesions. Clearly, these possibilities require further exploration and testing among larger populations. 
This work was supported in part by a Public Health Research and Development Committee Fellowship from the National Health and Medical Research Council, and the Mayne Bequest Fund, University of Queensland.

1 Bonelli L, Martines H, Conio M, Bruzzi P, Aste H. Family history of colorectal cancer as a risk factor for benign and malignant tumours of the large bowel. A case-control study. Int $\mathcal{F}$ Cancer 1988; 41: 513-7.

2 Morson BC. The polyp-cancer sequence in the large bowel. Proc R Soc Med 1974; 67: 451-7.

3 Mecklin J-P. Frequency of hereditary colorectal carcinoma. Gastroenterology 1987; 93: 1021-5.

4 Jass JR, Stewart SM. Evolution of hereditary non-polyposis colorectal cancer. Gut 1992; 33: 783-6.

5 Muto T, Bussey HJR, Morson BC. The evolution of cancer of the colon and rectum. Cancer 1975; 36: 2251-70.

6 Jass JR, Sobin LH. Histological typing of intestinal tumours: WHO International classification of tumours. Berlin: Springer-Verlag, 1989.

7 Aitken JF, Bain CJ, Ward M, Siskind V, MacLennan R. How accurate is self-reported family history of colorectal cancer? Am 7 Epidemiol 1995; 141: 863-71.

8 Schlesselman JJ. Case-control studies. Oxford: Oxford University Press, 1982: 177-9.

9 International Collaborative Group on HNPCC. Dis Colon Rectum 1991; 34: 424-5.

10 Kune GA, Kune S, Read A, MacGowan K, Penfold C, Watson LF. Colorectal polyps, diet, alcohol, and family history of colorectal cancer: a case-control study. Nutr Cancer 1991; 16: 25-30.
11 Maire P, Morichau-Beauchant M, Drucker J, Barboteau M, Barbier J, Matuchansky C. Prevalence familiale du cancer du colon et du rectum: resultats d'une enquete

12 Ponz de Leon M, Antonioli A, Ascari A, Zanghieri G, Ponz de Leon M, Antonioli A, Ascari A, Zanghieri G,
Sacchetti C. Incidence and familial occurrence of colorectal cancer and polyps in a health-care district of northern Italy. Cancer 1987; 60: 2848-59.

13 Fisher G, Armstrong B. Familial colorectal cancer and the screening of family members. Med F Aust 1989; 150: 22-5.

14 Guillem JG, Forde KA, Treat MR, Neugut AI, O'Toole KM Diamond BE. Colonoscopic screening for neoplasms in asymptomatic first-degree relatives of colon the colon cancer patients. A controlled, prospective study. Dis Colon

15 Grossman S, Milos ML. Colonoscopic screening of persons with suspected risk factors for colon cancer I. Family ,

16 Gaglia P, Atkin WS, Whitelaw S, Talbot IC, Williams CB, Northover JMA, et al. Variables associated with the risk of colorectal adenomas in asymptomatic patients with a family history of colorectal cancer. Gut 1995; 36: 385-90.

17 Cannon-Albright LA, Skolnick MH, Bishop DT, Lee RG, Burt RW. Common inheritance of susceptibility to colonic adenomatous polyps and associated colorectal cancers. N Engl ₹ Med 1988; 319: 533-7.

18 Lovett E. Family studies in cancers of the colon and rectum. Br $\mathcal{F}$ Surg 1976; 63: 13-8.

19 Houlston RS, Murday V, Harocopos C, Williams CB, Slack J. Screening and genetic counselling for relatives of patients with colorectal cancer in a family cancer clinic. $B M \Im$ 1990; 301: 366-8. 